\title{
O PROJETO EDUCACIONAL E OS SABERES AFRO-INDÍGENAS
}

THE EDUCATIONAL PROJECT AND AFRO-INDIGENOUS KNOWLEDGE

Hilson Santos Olegario. ${ }^{1}$

\begin{abstract}
RESUMO: Este artigo faz uma abordagem da construção histórica ideológica da educação brasileira desde sua ausente política educacional colonial até a recente entrada em vigor das Leis N. ${ }^{\circ} 10.639 / 2003$ e N. ${ }^{\circ} 11.645 / 2008$. Buscando denunciar as violências impostas por séculos por este modelo político educacional utilizando as suas próprias ferramentas oferecidas, com as quais temos a oportunidade de corrigir seu autoritarismo pretensioso hegemônico a partir da valorização das referências centradas nos saberes indígenas e afrocentrados.
\end{abstract}

Palavras-chave: Políticas Públicas, culturas híbridas, pedagogia das encruzilhadas.

ABSTRACT: This article approaches the historical ideological construction of Brazilian education from its absent colonial educational policy to the recent entry into force of Laws 10.639 / 2003 and 11.645 / 2008. Seeking to denounce the violence imposed for centuries by this political educational model using its own offered tools, with which we have the opportunity to correct its pretentious hegemonic authoritarianism by valuing references centered on indigenous and Afrocentered knowledge.

Keywords: Public policies, hybrid cultures, crossroads pedagogy.

\section{INTRODUÇÃO}

No Brasil, a educação como política pública nos três primeiros séculos de sua colonização era inexistente, e como resultado desta postura da Metrópole ficou a cargo dos religiosos cristãos que em sua grande maioria eram jesuítas, a formação educacional das famílias latifundiárias e das famílias dos servidores administrativos da Coroa Portuguesa. Porém, além da educação destas famílias, outra e principal função das missões era também a catequese dos povos pagãos, aonde eram transmitidas às instruções de civilidade, moral e ética da sociedade cristã colonial. De acordo com Freitag, os estabelecimentos de educação neste período como:

\begin{abstract}
Os colégios e seminários dos jesuítas foram desde o início da colonização os centros de divulgação e inculcação do cristianismo e da cultura europeia, ou seja, da ideologia do colonizador. Declaradamente sua função consistia em subjugar pacificamente a população indígena e tornar dócil a população escrava. (FREITAG, 1986, p. 47-48).
\end{abstract}

\footnotetext{
${ }^{1}$ Possui mestrado profissional em filosofia pela Universidade Federal de Pernambuco (2019.2), graduação em Filosofia (Licenciatura) pela Universidade Federal de Pernambuco (2012) e graduação em Filosofia (Bacharelado) pela Universidade Federal de Pernambuco (2012).
} 
Esta prática educativa presente durante todo o período colonial e imperial era diferenciada para os filhos dos latifundiários e agentes administrativos da Coroa, estes recebiam uma educação sob a Ratio Studiorum inspirada nas artes liberais do período clássico europeu para administrarem os bens da família ou seguirem a vida religiosa; enquanto que por outro lado não havia interesse no desenvolvimento da educação da população nativa e das matrizes africanas, pois somente após a chegada da República que em 1891, o Ministro da Instrução Pública, o Sr. Benjamin Constant decreta a laicidade da instituição e a gratuidade do ensino primário, porém, as bases da ideologia mencionada à cima por Freitag continuava sendo imposta tanto nas escolas como na vida social e religiosa do país. Pois, apesar de haver uma distinção entre a Igreja e o Estado, os ideais do pensamento iluminista ou a influência do positivismo com a ordem e o progresso; a educação das massas era voltada para suprir as necessidades de uma vida adulta a qual se organizava economicamente para as mesmas atividades extrativas e agrícolas dos períodos anteriores.

O "fim” da escravidão, abolida legalmente no Brasil em 1888, não modificou a mola da economia nacional que continuava a monocultura agroexportadora e a atividade extrativista. Para tal manutenção econômica o governo brasileiro adota a política de branqueamento da população, fundamentada no mito da superioridade da raça do colonizador europeu e destarte buscou-se suprir a necessidade de mão de obra, agora assalariada, composta preferencialmente de imigrantes europeus que recebiam doações de terras e incentivos fiscais desde os tempos do Império até meados da segunda década de 1900. O economista Celso Furtado nos relata que:

As colônias criadas em distintas partes do Brasil pelo governo imperial careciam totalmente de fundamento econômico tinham como razão de ser a crença na superioridade inata do trabalhador europeu, particularmente daqueles cuja "raça" era distinta da dos europeus que haviam colonizado o país. (FURTADO, 2005, p. 126).

Estas manutenções ideológicas, econômicas e sociais que permanecem mesmo com as mudanças na forma e sistema de governo, apontam desde muito tempo para o quanto que a população brasileira está distante das decisões políticas do país. O povo brasileiro passou de súdito a cidadão sem percorrer caminho algum e ainda não consegue perceber o que isto representa. Este incentivo relatado por Furtado se mantém até a década de 20 do século XX quando já se tem início o movimento folclorista no Brasil em busca de uma identidade nacional no seio das culturas populares já que o pensamento erudito era um decalque do europeu.

Mas foi apenas em 14 de novembro de 1930, quando então Getúlio Vargas cria através do Decreto No 19.402 o primeiro Ministério dos Negócios da Educação e Saúde Pública. Aonde junto a sua política de industrialização e de defesa nacionalista, o Ministro Capanema demonstra o interesse em "formar um exército de jovens trabalhadores", toda via, o que se observou na prática 
foi o encaminhamento dos jovens filhos das classes menos favorecidas para tal tipo de formação nos Liceus e Escolas Técnicas, onde estes finalmente "terminavam" os estudos. E, em contra partida, os jovens oriundos das famílias da emergente burguesia industrial, dos militares e da aristocracia rural eram direcionados para as instituições de ensino superior como Faculdades e Escolas Militares. O filósofo e pedagogo brasileiro Demerval Saviane salienta que:

O importante do ponto de vista político a salientar aqui é que nessa fase do entusiasmo
pela educação se pensava a escola como instrumento "de participação política", isto é, se
pensava a escola como uma unção explicitamente politica; a primeira década desse século,
a segunda, a década de 10 , e a terceira, a década de 20 , foram muito ricas em movimentos
populares que reivindicavam uma participação maior na sociedade, e faziam
reivindicações também do ponto de vista escolar. Nós sabemos que a década de 20 foi
uma década de grande tensão, de grande agitação, de crise de hegemonia das oligarquias
até então dominantes. Essa crise de hegemonia foi de certo modo aguçada pela
organização dos trabalhadores; várias greves operárias surgiram nesse período e vários
movimentos organizacionais também se deram. (SAVIANE, 1989, p. 56).

Podemos observar que aconteceram muitas mudanças na política educacional brasileira desde a sua inexistência até uma perspectiva de participação política e ascensão social, tivemos avanços e retrocessos como a criação das LDB’s de 1961, de 1971 até a chegada da Lei N. ${ }^{\circ}$ 9.394, em vigor desde 1996. No entanto, estas modificações foram impostas hierarquicamente e apesar das lutas dos setores da educação, da sociedade civil organizada descrita por Saviane, estas transformações foram realizadas através das propostas e acordos dos governos que se alternavam no poder visando à manutenção do status quo, desta maneira direcionando os estudantes ou para uma formação de mão de obra para o mercado de trabalho, ou para uma formação intelectual.

É importante observar que ambas as formações buscavam a um aprendizado imposto homogeneamente para os estudantes em toda a extensão e diversidade de um país continental como o Brasil. Baseadas nas teorias curriculares americanas reproduzia-se uma educação sem conexão e distante das diferentes realidades vividas em cada domicílio, quilombo, aldeia ou rua deste imenso território brasileiro, que não respeita as suas diversas vivências de fazeres e de saberes diferentes da racionalidade ocidental colonizadora. Nesta perspectiva, ao longo do tempo a política educacional tem procurado uma produção e reprodução no processo da formação dos estudantes que não respeita a diversidade existente na população brasileira. Levando o desenvolvimento educacional a ser direcionado apenas por uma lógica binária que se estende no Brasil desde a atividade colonial, a qual a partir dos anos de 1500 violenta vidas, línguas, costumes, saberes de povos indígenas e de povos vindos do continente africano.

No entanto, o árido trajeto iniciado nas disputas políticas educacionais que resultaram nas políticas de inclusão dos negros, dos indígenas e dos pobres nas instituições de ensino superior começa a dar frutos, através da verdade entendida como possibilidades de vários caminhos, como movimento anti-hegemônico esta política é desterritorializada e assentada numa encruzilhada com 
outras possibilidades. Pois, promulgada em 2003, a Lei N. 10.639 que faz alterações na LDB, Lei N. ${ }^{\circ}$ 9.394/96, tornando obrigatório nos níveis Fundamental e Médio dos estabelecimentos públicos ou particulares de ensino o estudo da História e Cultura afro-brasileira; posteriormente, alterada e ampliada em 2008 através da Lei N. ${ }^{0}$ 11.645, a qual inclui os estudos da História e Cultura indígenas nesta obrigatoriedade no âmbito de todo o currículo escolar, em especial nas áreas de educação artística e de literatura e história brasileiras; estas Leis abriram os caminhos para as vozes silenciadas durante séculos de imposição monológica de mundo poderem se posicionar e contar as suas próprias histórias, com suas próprias lógicas e magias.

Assim, além de representarem um marco importante na história contemporânea da construção curricular brasileira, pois sinalizam um rumo da política educacional em direção de uma valorização dos saberes e fazeres de povos violentados e subjugados na construção histórica nacional desde o início da colonização brasileira. Também nos mostram as cicatrizes, os epistemicídios realizados pelo projeto colonial, pois sua publicação evidencia a falta do aparelhamento do poder público e privado para acolher tais demandas devido ao silenciamento institucional e social histórico, a falta de conhecimento e de formação dos profissionais da educação em relação aos conteúdos das disciplinas ao tratarem dos temas que se referem à História e Cultura Afro-Indígenas, geralmente reduzidas a caricaturas preconceituosas ou tipo de informações vagas sobre o dia do Índio ou o dia da Consciência Negra.

Somos do pensamento em que a formação do professor não acaba na faculdade, neste sentido ela sempre será insuficiente. $\mathrm{Na}$ faculdade o estudante torna-se um profissional habilitado à docência dentro de um horizonte disponível didático, teórico e metodológico. Por isto sua formação neste entendimento se dá ao longo de sua vida profissional iniciada com os estágios docentes e nesta perspectiva, a formação continuada é uma necessidade inerente ao professor que se vê pesquisador, que sabe que há transformações na vida, que há produção de novos conhecimentos e que novas respostas surgem como num campo de mandinga.

\section{DEIXA A GIRA GIRÁ}

Apesar da explosão recente de textos sobre a temática da História e Cultura Afro-Indígena, sua produção mesmo que entusiasmada, ainda está no início do caminho, pois muitos dos saberes e dos modos de ser dessas culturas seguem uma lógica muito distinta do pensamento ocidental e de sua dualidade que busca ser hegemônica; pois, além de serem transmissões orais necessitando de uma vivência dentro daquelas práticas corporais, rituais e de fala; o conceito dual ocidental colonizador também necessita passar pela boca de Exu e ser vomitado em muitos outros caminhos 
junto com toda a contradição que sustenta estes povos apesar das opressões que lhes são impostas. No decurso destes primeiros quinhentos anos estes saberes foram muitas vezes perseguidos e tirados de contextos tanto dentro da visão religiosa, a qual a cristandade condenou tais práticas ao inferno, como também foram chamados de maldosos, bárbaros e primitivos por se contrapor a lógica de dominação ocidental.

Mas a nossa proposta não é a de tornar-se a régua do mundo como uma verdade hegemônica, muito pelo contrário, já que tal posicionamento é justamente o que estamos denunciando. Diante do vasto horizonte de caminhos que se cruzam nas tradições afro-indígenas no Brasil, nos propomos a trabalhar em prol de que tais agentes possam escrever suas próprias histórias e saberes, respeitando seus mistérios, mas que o que seja produzido de material, de ferramenta educativa sobre estes povos não seja desenvolvido por uma visão externa a comunidade, a qual será catalogada, enquadrada segundo critérios e parâmetros distintos de suas práticas e saberes.

\section{O FUNDAMENTO É OUTRO}

Por se movimentar com outra perspectiva, para se entender a lógica iyorubá que se hibridizou com as lógicas indígenas no Brasil é necessário saber inicialmente que o pensamento ocidental colonizador não as contempla. Tanto na sua impotência de sair da dualidade inerente a sua imposição como "bem x mal", "civilização x barbárie", "esquerda x direita", "mente x cérebro" como também pela concepção fixa de falsa universalidade moral e ética a qual ele se sustenta. Que a seu modo as catalogou de acordo com o seu discurso hegemônico como selvagens, perversas, levando-as muitas vezes a ilegalidade, restando-nos como documentação oficial, constantemente, os boletins de ocorrências policiais com os nomes dos vadios dentre outros adjetivos desqualificáveis empregados a quem se opunha a tal proposta civilizatória. Por isso, José Rufino em sua tese de doutorado que transformada em livro: Pedagogia das encruzilhadas: Exu como educação, nos destaca previamente as dificuldades para firmar o ponto, dizendo:

\footnotetext{
Ressalto que há esforços para a apresentação e o curso de outras perspectivas epistemológicas e filosóficas, porém, ainda existem inúmeras dificuldades e desproporções no que tange às relações horizontais entre o que é produto do cânone moderno ocidental e as outras formas de conhecimento possíveis. Neste sentido, cabe cismarmos com as respostas até então dadas e considerarmos que grande parte dos conhecimentos orientados pelo discurso científico moderno é limitado a saberes etnocentrados. (RUFINO, 2019, p. 39).
}

Diante da perspectiva levantada por Rufino, o pensamento moderno ocidental que se pretende hegemônico é na verdade um pensamento etnocentrado que se esforça para se impor 
diante a horizontalidade humana dos demais. Devido a tal pretensão devemos cismar com tal imposição de valores e buscar superar as dificuldades desta verticalização eurocentrada ao propormos outras epistemologias e filosofias, apresentando conhecimentos possíveis e inconcebíveis diante a racionalidade ocidental. Não para trocar de lugar um saber pelo outro, e sim para demonstrar a possibilidade de coexistência de saberes diferentes, saberes que comportam as contradições entre a concretude dos afazeres e a mágica da existência como nos relata o professor doutor Daniel Munduruku que para ele:

\begin{abstract}
Foi vivendo a totalidade dessa cultura que descobri que a educação indígena é muito concreta, mas é ao mesmo tempo mágica. Ela se realiza em distintos espaços sociais que nos lembram sempre que não pode haver distinção entre o concreto dos afazeres e aprendizados e a mágica da própria existência que se "concretiza" pelos sonhos e pela busca da harmonia cotidiana. Isso, é claro, pode parecer contraditório à primeira vista, mas segue uma lógica bastante compreensível para nossos povos, pois não é uma negação dos diferentes modos de coexistência como se tudo fosse uma coisa única, mas um modo da mente operacionalizar o que temos a pensar e viver. (MUNDURUKU, 2009, p. 23).
\end{abstract}

Por muitos anos o ocidente falou destes e outros povos, por estes povos, sobre estes povos com a sua lente única do conhecimento gerando imposições, explorações, extermínios; no auge dos desenvolvimentos intelectuais europeus do modernismo e do iluminismo tivemos o colonialismo sendo implementado, reprimindo culturas e sonhos em busca de satisfazer o acumulo e a insaciedade econômica do mercantilismo chegando ao capitalismo; mas a hora grande chegou.

E neste sentido, estas produções acadêmicas recentes se justificam na paciência dos pretos velhos que acolhidos pelos indígenas, utilizaram os santos católicos para expressar a sua devoção aos orixás, transformando-a, fundamentada na contradição que se assenta no sincretismo religioso que utiliza a fé do colonizador como ferramenta de fortalecimento da sua ancestralidade. Que estes trabalhos sirvam de ferramenta que auxilie educadores, pesquisadores e demais interessados no tema, mas principalmente também para que a memória, as práticas e as suas explicações de mundo possam ser expressas sem apagamentos históricos, buscando uma fuga para se libertar do que aprisiona e os mantem cativos entre a cruz e a espada.

\title{
O QUE NÃO MATA, FORTALECE
}

Observando a partir de um enfoque bibliográfico, começando por um levantamento e leitura de textos buscando uma compreensão elucidativa histórica de nossa problemática, no intuito de perceber via uma apropriação dos movimentos políticos e sociais que ocorreram e ocorrem no processo de formação da sociedade brasileira os dispositivos autoritários desta lógica ocidental eurocentrada que colonizou o país. Podemos apontar que estes movimentos são sistematizados por teorias filosóficas e científicas que têm elaborado uma educação como mecanismo de 
conservação e de manutenção da sociedade capitalista exploradora que segue esta mesma linha de raciocínio impositivo de pretensão universal.

Como as vozes das matrizes afro-indígenas, silenciadas desde o início do projeto de colonização europeu, possam através da Lei 11.645/2008 e dos pareceres 03/2004 e 14/2015 expressar seus pensamentos, ampliando as bases teóricas para uma educação evitando distorções históricas na luta contra o racismo?

Com o fundamento no movimento exuístico estamos utilizando as próprias engrenagens do pensamento eurocentrado para engoli-lo e depois vomitá-lo transformado em novos caminhos. Chamamos o francês Michael Foucault (1926-1984) que expõe minuciosamente a forma como os sistemas de dominação foram historicamente construídos em seu livro: História da sexualidade: vontade de saber (1999). E com base na análise das relações de poder realizada na obra: Microfísica do poder (1984) pode ser visto as dificuldades de se desprender dos vínculos criados com o enraizamento do poder que constroem e modificam a experiência que os indivíduos têm de si mesmo, junto com a sua denúncia da criação das escolas, prisões e hospícios em seu livro Vigiar e punir (1987) Foucault nos diz que:

O poder disciplinar é com efeito um poder que, em vez de se apropriar e de retirar, tem como função maior "adestrar"; ou sem dúvida adestrar para se apropriar e retirar ainda mais e melhor. Ele não amarra as forças para reduzi-las; procura ligá-las para multiplicálas e utilizá-las num todo. (FOUCAULT, 1987, p.143).

Foucault procura evidenciar o fato de que a disciplina na escola funciona como "fábricas" de indivíduos, "adestrando" multidões diversas com técnicas específicas aonde estes indivíduos são tomados como objetos e como instrumentos de reprodução, provocando assim a degeneração da singularidade da pessoa ou o assujeitamento. Ele chama a atenção de que essa estrutura não se trata mais de um poder de excesso, com um superpoderio, e sim modesto, que funciona de modo permanente com procedimentos menores e mais humildes, caso tomados como referência à majestosa soberania ou aos grandes aparelhos do Estado, no entanto, são justamente estes processos que vão pouco a pouco invadindo as formas maiores, modificando-lhes os mecanismos e impondo-lhes seus processos.

Através de seu amigo e também pensador contemporâneo, o francês Gilles Deleuze (1925-1995), encontramos uma crítica à imposição de uma pretensa ordem universal, fundamentada por uma unidade de relações binárias encontrada no seu livro: Mil platôs: capitalismo e esquizofrenia (2000), onde é denunciada a verticalidade de um modo de saber, chamado por ele de arborecente, o qual é impositivo, hierárquico e de pretensões hegemônicas originando-se a partir de uma lógica reproduzida no ocidente a qual é apontada por ele como pivotante. Em contra partida, é proposta uma outra visão horizontal conceituada por Deleuze como 
rizomática que é desenvolvida posteriormente em seu trabalho: O que é a filosofia? (2010); no qual para ele através de movimentos de desterritorialização e reterritorialização os conceitos vão ganhando outra amplitude, modificando seu plano de imanência, tornando-se mais atualizados e com pontos de fuga que possibilitam uma ruptura com o modelo de pensamento binário, autoritário, impositivo e homogêneo.

As multiplicidades são a própria realidade, e não supõem nenhuma unidade, não entram
em nenhuma totalidade e tampouco remetem a um sujeito. As subjetivações, as
totalizações, as unificações são, a contrário, processos que se produzem e aparecem nas
multiplicidades. Os princípios característicos das multiplicidades concernem a seus
elementos, que são singularidades; a suas relações, que são devires; a seus acontecimentos,
que são hecceidades (quer dizer, individuações sem sujeito); a seus espaços-tempos, que
são espaços e tempos livres; a seu modelo de realização, que é o rizoma (por oposição ao
modelo da árvore); a seu plano de composição, que constitui platôs (zonas de intensidade
contínua); aos vetores que as atravessam, e que constituem territórios e graus de
desterritorialização. (DELEUZE, 2000, p.08).

Com esta revisita bibliográfica tratando sobre as questões que edificaram a torre narcísica do pensamento ocidental eurocentrado, propomos buscar a partir deste mesmo pensamento ferramentas conceituais que o combata enquanto imposição hegemônica, investindo em uma desterritorialização desta compreensão buscando uma reterritorialização com outro fundamento, neste sentido, com sua base erguida a partir de uma perspectiva afrocentrada, ou seja, fundamentada nas reverberações da diáspora africana, o resultado não pretendido da exploração colonial europeia e suas hibridações do lado de cá do Atlântico.

Para isso, invocamos primeiramente Frantz Fanon (1925-1961), psicanalista martinicano e ativista nas revoluções de libertação das colônias francesas que estudou as psicopatologias desenvolvidas nos povos colonizados em regime de escravidão. Em seu livro: Pele negra máscaras brancas (2008), Fanon desenvolve uma crítica histórica dos resultados do racismo e da desumanização na psique humana dos povos que foram subjugados, sendo produto dessa perspectiva violências de ambos os lados desta dicotomia entre colonizadores $\mathrm{x}$ colonizados minimizadas com uma busca por igualdade no processo de dominação colonial, assim para ele:

Como se vê, fazendo-se apelo à humanidade, ao sentimento de dignidade, ao amor, à caridade, seria fácil provar ou forçar a admissão de que o negro é igual ao branco. Mas nosso objetivo é outro. O que nós queremos é ajudar o negro a se libertar do arsenal de complexos germinados no seio da situação colonial. (FANON, 2008, p. 44)

Na procura de tal exercício de libertação dos complexos gerados pela situação colonial citado por Fanon, tem início nos anos de 60 do século XX, nos Estados Unidos, a proposição e o estudo de um novo paradigma baseado na afirmação de sentido existencial do povo africano, formulando novos métodos centrados no pensamento africano para analisar as informações, Molefi Kete Asante publica em 1980 o livro: Afrocentridade: a teoria da mudança social; gerando um movimento de deslocamento do pensamento eurocêntrico para a encruzilhada de pensamentos 
afrocentrados. As contribuições de Fanon e Asante dentre outros pensadores são a evidência deste processo de descolonização e antirracismo que não busca uma unidade fictícia, pois percebem a influência do ambiente e da hibridização com outros povos no modo de construção de seus saberes e fazeres, e assim, ao invés da imposição da unidade política o afrocentrismo busca a coletividade já que para Asante:

Desde o século dezoito nossos pensadores buscaram nossa unidade política (Walker, 1965). Essa provou ser uma falsa esperança porque perseguir ilusões nos tornou cansados da retórica da unidade. Não é a unidade que devemos buscar, mas a consciência coletiva. (ASANTE, 2003, p. 42).

Esta consciência de coletividade ressaltada por Asante, apesar de ter sido publicada na literatura recentemente junto com a perspectiva afrocentrada, ela vem sendo praticada em muitos territórios espalhados com a diáspora africana pelas Américas desde o período colonial, primeiro nas aldeias e senzalas, mas posteriormente nos terreiros de religiões de matriz africana espalhados pelo Novo Mundo, estas casas de força tem papel importante na manutenção da tradição junto aos seus saberes e fazeres do culto aos orixás e a ancestralidade.

Diante tal cenário, a compreensão da diversidade do pensamento afro-indígena nas Américas precisa alcançar patamares cada vez mais abrangentes no sentido de seu entendimento, derrubando os preconceitos que envolvem nossa herança histórica colonial, imperial e republicana de exploração do homem pelo homem, assim, nós conclamamos demais pesquisadores a produzirem através de um diálogo entre as matrizes afro-indígena e o conhecimento acadêmico para podermos descrever as concepções que demonstram a versatilidade de Exu em andar criando novos caminhos, transformando e ressignificando o movimento como força vital entre a humanidade.

\section{FECHANDO A GIRA}

Tendo o entendimento de que o pensamento afrocentrado apesar de enfrentar o pensamento eurocentrado em sua imposição hegemônica e universalização binária, não é por isso entendido como única resposta possível e nem busca silenciar outras vozes dentre as explicações de mundo. No entanto, acreditamos que só uma educação acolhedora que compreenda com amplitude empática a diversidade dos modos de ser e de estar no mundo dos indivíduos, os quais são desenvolvidos pelas suas civilizações em diversos territórios e em tempos diferentes, possa indicar um caminho para uma superação deste modelo de sociedade imposto no Brasil desde 1500 da era cristã. Ao invés de combater em frentes de lutas que não são as nossas, registradas pelo projeto colonizador como avanço civilizatório, o qual durante séculos desprezou e buscou eliminar 
nossos saberes podemos ressaltar também o médico e antropólogo colombiano Manuel Zapatta Olivella, que em seu livro Changô: El gran putas (1983) menciona uma atitude tomada por alguns combatentes de um mesmo agrupamento militar para esta guerra ideológica:

Pedimos uma só exigência militar: usar penas em nossas cabeças ou chapéus. Para o oficial branco deve constituir uma ingenuidade índia. Nós sabíamos que com esses emblemas mágicos seríamos protegidos por nossos ancestrais guerreiros. (OLIVELLA, 1983 , p. 604 - tradução livre).

Deste jeito, munidos com os seus patuás tais produções acadêmicas e educacionais que visam suprir as demandas oriundas da luta pela implementação das Leis N. ${ }^{\circ} 10.639 / 2003$ e N. ${ }^{\circ}$ 11.645/2008 nos moldes de seus pareceres representam a volta da ancestralidade que se reinventa nas novas gerações mantenedoras das tradições. Neste sentido, é mister saber que a ancestralidade não se configura como um conjunto inflexível de sanções de cunhos morais ou também que a sua transmissão não é exclusivamente genética, ao contrário, sendo um modo de vida, de pensar e de fazer construído através da tradição, ela torna-se portadora de construções e desconstruções numa história de equilíbrio e desequilíbrio na composição das identidades.

\section{REFERÊNCIAS BIBLIOGRÁFICAS}

ASANTE, M. K. Afrocentridade: a teoria de mudança social. Tradução: Ana Monteiro-Ferreira, Ama Mizani e Ana Lúcia. Philadephia: Afrocentricity, 2014.

DELEUZE, G. GUATTARI, F. O que é a filosofia?. Tradutor: Bento Prado Jr.Alberto Alonso Munoz. 3a ed. São Paulo: Editora 34, 2010.

2000.

G.; GUATTARI, F. Mil platôs: capitalismo e esquizofrenia. 2a ed. São Paulo: Editora 34,

FOUCAULT, Michel. História da sexualidade: vontade de saber. Tradução: Maria Thereza da Costa Albuquerque e J. A. Guilhon Albuquerque. 13ª ed. Rio de Janeiro: Graal. 1999.

Graal, 1984.

Michel. Microfísica do poder. Org. Tradução: Roberto Machado. $4^{\mathrm{a}}$ ed. Rio de Janeiro:

, Michel. Vigiar e punir: nascimento da prisão. Tradução Raquel Ramalhete. Petrópolis: Vozes, 1987.

MOURA, C. Sociologia do negro brasileiro. São Paulo: Ática, 1988.

RUFINO, Luiz. Pedagogia das encruzilhadas. Rio de Janeiro: Mórula Editorial, 2019.

SAVIANI, D. Escola e democracia: Teorias da educação, Curvatura de vara, Onze teses sobre educação e política. 22ª ed. São Paulo: Cortez, 1989. 
SILVA, Tomaz Tadeu da. Documento de identidade: uma introdução às teorias do currículo. 2a ed. Belo Horizonte: Autêntica, 2005.

\section{TESES E DISSERTAÇÕES}

OLIVEIRA, Eduardo David de. Filosofia da ancestralidade: corpo e mito na filosofia da Educação Brasileira- UFC. 2005. 353f. - Tese (Doutorado) - Universidade Federal do Ceará, Programa de Pós-graduação em Educação Brasileira, Fortaleza (CE), 2005. Disponível em: $<$ http://www.repositorio.ufc.br/handle/riufc/36895 > Acesso: 30.set.2020.

REIS, Maurício de Novais; FERNANDES, Alexandre de Oliveira. AFROCENTRICIDADE: Identidade e centralidade africana. ODEERE, [S.1.], v. 3, n. 6, p. 102-119, dez. 2018. ISSN 25254715. Disponível em: <http://periodicos2.uesb.br/index.php/odeere/article/view/4302>. Acesso em: 18 ago. 2020.

\section{LEIS}

BRASIL, Lei de Diretrizes e bases da Educação nº 9.394/96. Define as diretrizes e bases da educação. Diário Oficial da União. Seção 1 - 23 dez. 1996, Página 27833.

BRASIL, Lei $\mathrm{n}^{\circ}$ 10.639/2003. Altera a Lei $\mathrm{n}^{\circ}$ 9.394/96, inclui a obrigatoriedade da temática "História e Cultura Afro-Brasileira.

BRASIL, Lei $n^{\circ} 11,645 / 2008$. Altera a Lei ${ }^{\circ}$ 9.394/96, modificada pela Lei ${ }^{\circ} 10.639$ estabelece a orbigatoriedade das temáticas Afro-Brasileiras e Indígena. 